\title{
Ground deformation source model at Kuchinoerabu-jima volcano during 2006- 2014 as revealed by campaign GPS observation
}

Kohei Hotta* ${ }^{*}$ and Masato Iguchi

\begin{abstract}
We analyzed campaign Global Positioning System observation data in Kuchinoerabu-jima during 2006-2014. Most benchmarks located around Shin-dake crater showed crater-centered radial horizontal displacements. Horizontal displacements at western rim of the Shin-dake crater were tended to be larger compared to those at eastern rim. In addition, benchmark KUC14 which locates near the cliff at Furu-dake showed westward horizontal displacement rather than crater-centered radial (southward) one. Meanwhile, small displacements were detected at the benchmarks located at the foot of Kuchinoerabu-jima. We modeled the observed displacements applying a finite element method. We set entire FE domain as $100 \times 100 \times 50 \mathrm{~km}^{3}$. We set top of the domain as a free surface, and sides and bottom to be fixed boundaries. Topography was introduced in the area within Kuchinoerabu-jima using digital elevation model data provided by Kagoshima prefecture and elevation information from Google earth, and elevation of the outside area was assumed to be sea level. We assumed a stratified structure based on a one-dimensional P-wave velocity structure. We applied a vertical spheroid source model and searched optimal values of horizontal location, depth, equatorial and polar radiuses, and internal pressure change of the source using the forward modeling method. A spherical source with a radius of $50 \mathrm{~m}$ was obtained beneath the Shin-dake crater at a depth of $400 \mathrm{~m}$ above sea level. The internal pressure increase of $361 \mathrm{MPa}$ yields its volume increase of $31,700 \mathrm{~m}^{3}$. Taking effects of topography and heterogeneity of ground into account allowed reproduction of overall deformation in Kuchinoerabujima. The location of deformation source coincides with hypocenters of shallow volcano-tectonic (VT) earthquakes and the aquifer estimated from a two-dimensional resistivity model by audio-frequency magnetotellurics method. The obtained deformation source may be corresponding to the pressurized aquifer, and shallow VT earthquakes and demagnetization may be caused by pressure and strain accumulation in the rocks around the aquifer. Applying the obtained spherical source to the tilt change before August 3, 2014 eruption, we found that $520 \mathrm{~m}^{3}$ of volcanic materials were supplied toward shallower in $1.5 \mathrm{~h}$ before the eruption. The depth and volume change of deformation source before May 2015 eruption detected by precise leveling surveys is deeper and two orders of magnitude greater compared to that before August 2014 eruption.
\end{abstract}

Keywords: Kuchinoerabu-jima, Campaign GPS observation, Finite element method

\section{Introduction}

Kuchinoerabu-jima is an andesitic volcano, south off Kyushu Island, Japan (Fig. 1). The volcano consists of three cones: No-ike, Shin-dake and Furu-dake; and the Shindake is presently active. Phreatic or phreato-magmatic

*Correspondence: hotta.kohei.7r@kyoto-u.ac.jp Sakurajima Volcano Research Center, Disaster Prevention Research Institute, Kyoto University, Kagoshima 891-1419, Japan eruptions occurred at the crater or a fissure east of it in 1841 (historically the oldest), 1931-1934, 1945, 1966, and 1980 (Triastuty et al. 2009). After 34 years dormancy, a phreatic eruption occurred at the Shin-dake crater on August 3, 2014. As shown in Fig. 2, the eruption was preceded by precursory phenomena for 15 years. Seismicity increased in July 1999, and ground inflation was detected by Campaign Global Positioning System (GPS) in 2001. Seismicity and ground inflation continued thereafter. The 
seismicity increase and inflation of ground were followed by increase in geothermal activity, as shown by enlargement of geothermal anomaly zone as well as temperature increase around Shin-dake after around 2003 (Iguchi 2007), and demagnetization of thermal storage beneath the crater (Kanda et al. 2010). In accordance with increase in geothermal activity, fumarole was firstly found at the crater bottom in 2003, and white smoke was activated at the south crater wall in 2008 when change rate in baseline length increased (Fig. 2; Iguchi and Nakamichi 2015).

Among the precursory activity, ground inflation detected by campaign GPS observations was significant. It is characterized by large displacements around Shindake crater in contrast to minimal changes at the foot of the volcano. This suggests a shallow source, and a source was obtained at a depth of $<300 \mathrm{~m}$ below sea level (bsl) under an assumption of Mogi-type source (Mogi 1958) in homogeneous half space (Iguchi et al. 2007). However, it is difficult to obtain size and shape of the spherical source which must be small enough compared to its depth, and homogeneous half space may not be realistic considering complicated surface topography near the crater. A number of studies have applied a finite element method (FEM) to the modeling of ground deformation in order to examine how topographical effects or heterogeneity of ground affect and found that such factors affect to the results of deformation source analysis (e.g., Zhao et al. 2004; Ronchin et al. 2015).

In the present study, we applied an FEM to the GPS observation data in Kuchinoerabu-jima in order to obtain more precise shape and depth of the deformation source, taking effects of surface topography and heterogeneity of ground into account. We then discussed about the obtained deformation source from previous studies of seismic data and geomagnetic field. Also, we applied the obtained deformation source to the precursor tilt change before the August 3, 2014 eruption in order to estimate the intrusion amount. Finally, we discussed about the volume change of the deformation source before the eruption on August 3, 2014, in order to compare with that before the eruption on May 29, 2015, estimated from precise leveling surveys.

\section{Observation and data analysis}

Location of GPS benchmarks in Kuchinoerabu-jima Island is shown in Fig. 1. KUCG at the foot is a continuous GPS station. In August 1995, six benchmarks (KUC1-6) were installed around Shin-dake crater, and seven (KUC7-13) installed at the foot. Location of KUC2 is a first-order triangulation point. In January 2006, two benchmarks (KUC14 and 15) were added on Furu-dake (KUC14) and fumarolic field SW of Shin-dake (KUC15), respectively. Campaign GPS observations have been done in August 1995; March, May, and August 1996; September 1999; December 2000; December 2001; March and April 2004; February 2005; December 2006; February 2007; January and December 2008; April 2009; February 2010; January and December 2011; December 2012; and April 2014. Data from KUC2 and KUC13 were not available after January 2006 and December 2000, respectively. KUC1 and KUC7-12 experienced relocations in 2001 and 2004, respectively. Coordinates (longitude, latitude, and elevation) of the benchmarks are listed in Table 1. Campaign observations were conducted for approximately $48 \mathrm{~h}$ at the foot and $2 \mathrm{~h}$ around Shin-dake and Furu-dake. Sampling intervals were every $15 \mathrm{~s}$. We used GPS receivers Leica SR399 and SR520. We used the software Leica Geo Office for baseline analysis. Leica Geo Office calculates daily position of each station assuming that the reference station does not change its position. In addition, it provides uncertainty of baseline length as the observation error. The reference of baseline analysis was set to be KUCG which is the only continuous GPS station among the data we used in the present study and is considered to have the highest quality.

\section{Characteristics of ground deformation}

Figure 3 shows temporal change of relative displacement of benchmarks with respect to KUCG during 1995-2014. Displacement became clear in 2001. Especially, KUC5 which locates west rim of Shin-dake crater moved $20 \mathrm{~cm}$ westward, $8 \mathrm{~cm}$ southward, and $20 \mathrm{~cm}$ upward during 2001-2014. After KUC14 and 15 were installed in 2006, rapid motions were detected in 20082009 and 2010-2013. Figure 4 shows relative horizontal and vertical displacements during January 2006-April 2014, when the most data were available, with respect to KUCG. Relative displacement with respect to KUCG and uncertainty of baseline length by Leica Geo Office for each benchmark are shown in Table 1. The uncertainty of change in baseline length between January 2006 and April 2014 was calculated as square-root of sum of squares of the uncertainty of baseline length for these two epochs. Most benchmarks located around the Shindake crater showed crater-centered radial horizontal displacements. There was a tendency that observed horizontal displacements at western rim of the Shin-dake crater were larger compared to those at eastern rim. In addition, benchmark KUC14 which locates near the cliff at Furu-dake (i.e., approximately $500 \mathrm{~m}$ south of the Shin-dake crater) showed westward horizontal displacement rather than crater-centered radial (southward) one. These characteristics cannot be explained by the simple Mogi model beneath Shin-dake crater as the previous studies did. On the other hand, small displacements with 


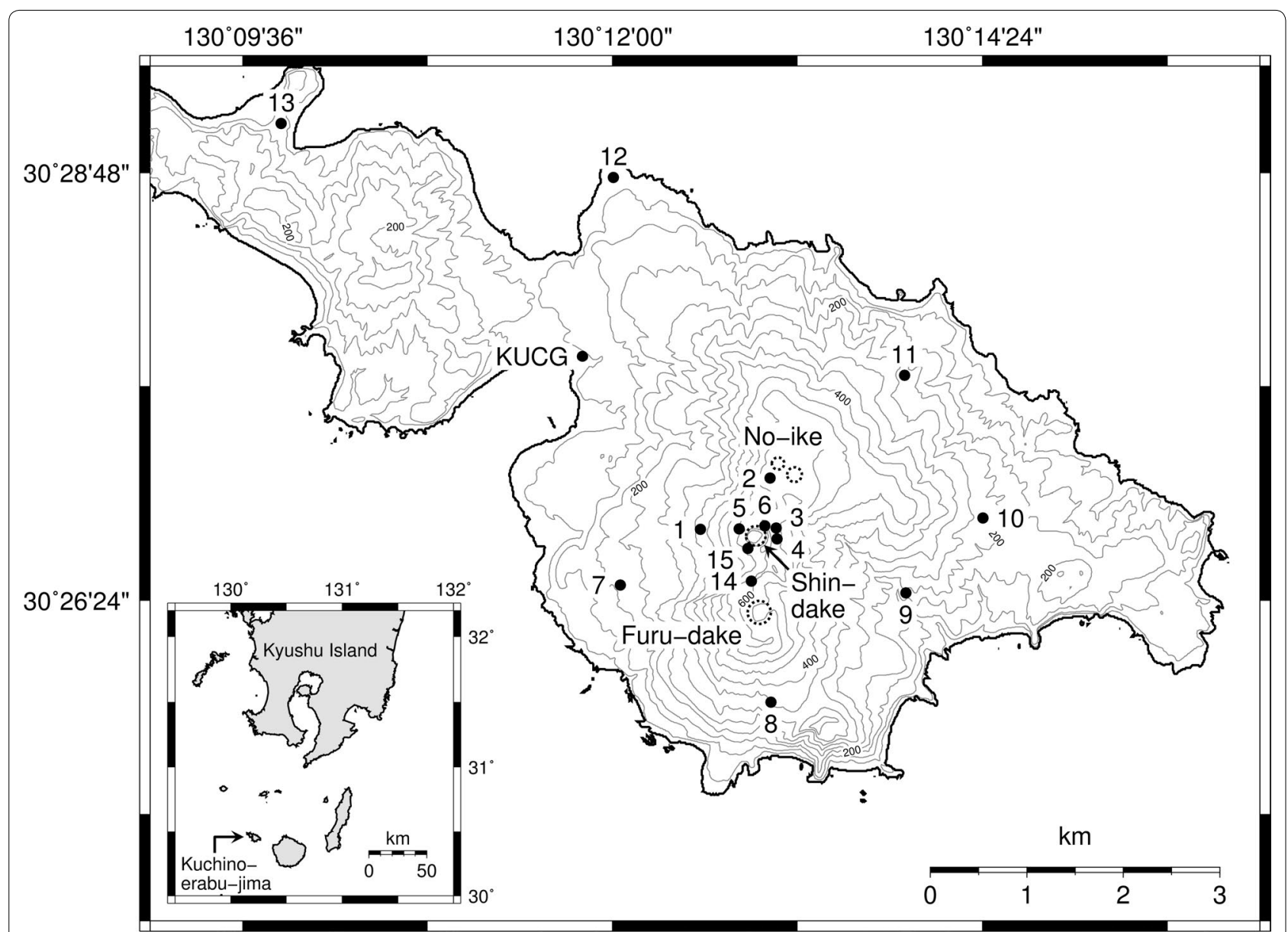

Fig. 1 Location of Kuchinoerabu-jima (bottom left) and distribution of GPS benchmarks (solid circles). Numbers 1-15 are corresponding to KUC1KUC15, respectively. Circles with dashed lines represent craters of No-ike, Shin-dake, and Furu-dake

less than $2 \mathrm{~cm}$ were detected at the benchmarks located at the foot of Kuchinoerabu-jima. This characteristic implies that the depth of deformation source is quite shallow.

\section{Methods and results}

\section{Finite element method}

In order to take topographic effects into account, we applied an FEM using the software Flex PDE Professional version 6.40 provided by PDE Solutions Inc. Figure 5 shows entire FE domain. We set the domain size as $100 \times 100 \times 50 \mathrm{~km}^{3}\left(129.7011-130.7351^{\circ} \mathrm{E}, 29.9911-\right.$ $\left.30.8994^{\circ} \mathrm{N}, 0-50 \mathrm{~km} \mathrm{bsl}\right)$. We set top of the domain as a free surface, and sides and bottom of the domain as fixed boundaries. As we used benchmarks inside Kuchinoerabu-jima in the present study, topography was introduced in the area within Kuchinoerabu-jima using digital elevation model (DEM) data provided by Kagoshima prefecture, and elevation of the outside area was assumed to be sea level (zero). Unfortunately, however, the DEM data provided by Kagoshima prefecture are lacking the data at southern foot of Kuchinoerabu-jima. Therefore, we complemented the lacking data using the elevation information from Google earth. The resolution of the DEM data from Kagoshima prefecture is $2.5 \mathrm{~m}$, and we converted it into $100-\mathrm{m}$ resolution. We got elevation from Google earth with the resolution of $100 \mathrm{~m}$, similarly to our converted DEM data.

In addition to topographic effect, we took heterogeneity of ground into account. Yamamoto et al. (2005) and Triastuty et al. (2009) assumed a one-dimensional P-wave velocity structure as shown in Table 2. Assuming a Poisson's ratio as 0.25 and $V_{\mathrm{P}} / V_{\mathrm{S}}$ velocity ratio as 1.73 , modulus of rigidity $\mu$ can be written as

$$
\mu=\frac{\rho V_{\mathrm{P}}}{3}
$$

where $\rho$ is the density of ground. Currenti et al. (2007) found the following empirical formula between the density of ground and P-wave velocity: 


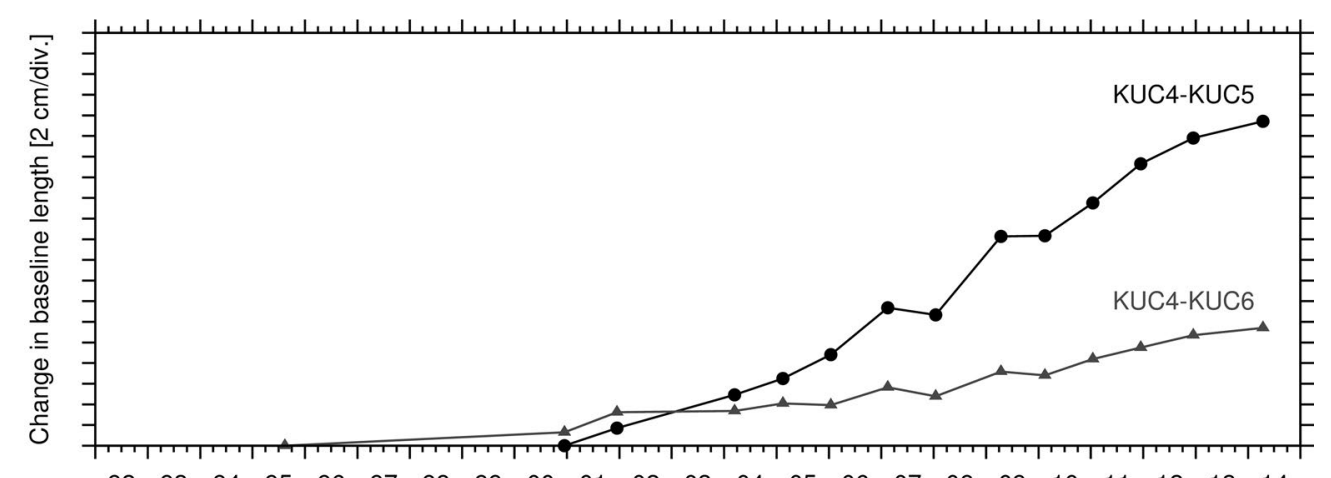

$\begin{array}{lllllllllllllllllllllll}92 & 93 & 94 & 95 & 96 & 97 & 98 & 99 & 00 & 01 & 02 & 03 & 04 & 05 & 06 & 07 & 08 & 09 & 10 & 11 & 12 & 13 & 14\end{array}$

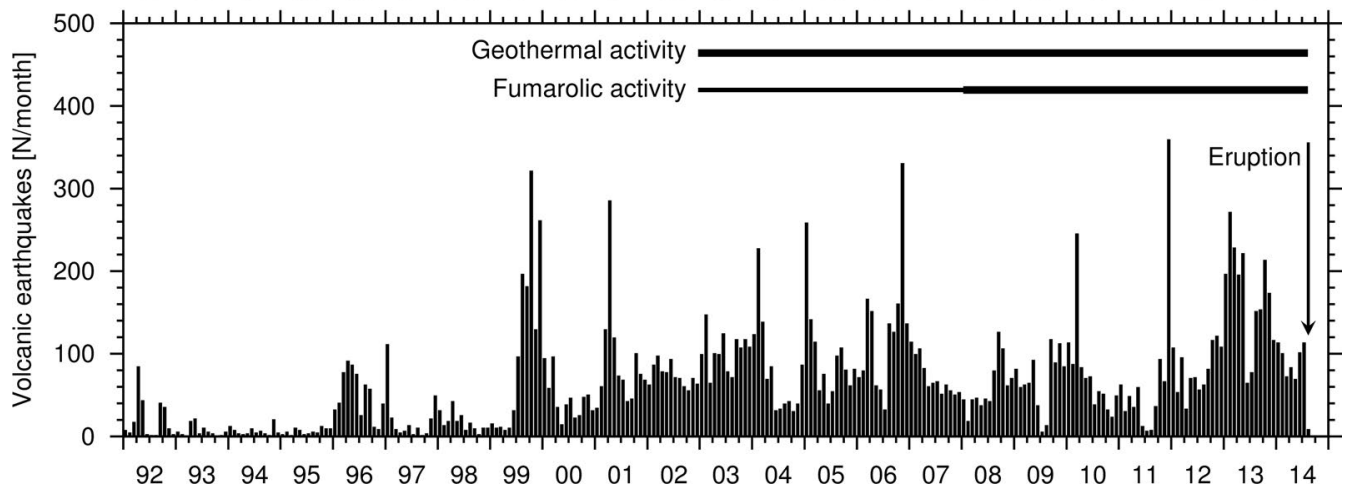

Fig. 2 Changes in baseline length (top) and monthly number of volcanic earthquakes with indication of geothermal and fumarolic activities (bottom) between 1992 and 2014

Table 1 Coordinates of GPS benchmarks at Kuchinoerabu-jima, relative displacements with respect to KUCG during January 2006-April 2014, and uncertainty of change in baseline length

\begin{tabular}{|c|c|c|c|c|c|c|c|}
\hline \multirow[t]{2}{*}{ Benchmark } & \multirow[t]{2}{*}{ Longitude $\left({ }^{\circ} \mathrm{E}\right)$} & \multirow[t]{2}{*}{ Latitude $\left({ }^{\circ} \mathrm{N}\right)$} & \multirow[t]{2}{*}{ Altitude ( $m$ asl) } & \multicolumn{3}{|c|}{$\begin{array}{l}\text { Relative displacement } \\
\text { with respect to KUCG }(\mathrm{m})\end{array}$} & \multirow[t]{2}{*}{$\begin{array}{l}\text { Uncertainty of change in baseline length } \\
\text { (m) }\end{array}$} \\
\hline & & & & $E-W$ & $\mathrm{~N}-\mathrm{S}$ & U-D & \\
\hline KUCG & 130.19674 & 30.46283 & 38.2 & - & - & - & - \\
\hline KUC1 & 130.20948 & 30.44666 & 381.4 & -0.045 & 0.010 & 0.021 & 0.028 \\
\hline KUC2 & 130.21702 & 30.45142 & 599.3 & - & - & - & - \\
\hline KUC3 & 130.21768 & 30.44677 & 575.2 & 0.052 & 0.016 & 0.034 & 0.035 \\
\hline KUC4 & 130.21777 & 30.44576 & 576.9 & 0.072 & -0.022 & 0.031 & 0.033 \\
\hline KUC5 & 130.21367 & 30.44667 & 555.3 & -0.144 & 0.066 & 0.123 & 0.024 \\
\hline KUC6 & 130.21644 & 30.44696 & 607.2 & 0.039 & 0.050 & 0.038 & 0.028 \\
\hline KUC7 & 130.20086 & 30.44142 & 165.9 & -0.013 & -0.007 & -0.042 & 0.017 \\
\hline KUC8 & 130.21713 & 30.43047 & 358.7 & -0.004 & -0.006 & -0.011 & 0.022 \\
\hline KUC9 & 130.23171 & 30.44069 & 183.3 & 0.006 & -0.008 & -0.023 & 0.020 \\
\hline KUC10 & 130.24001 & 30.44769 & 239.2 & -0.005 & -0.006 & -0.026 & 0.071 \\
\hline KUC11 & 130.23156 & 30.46102 & 230.8 & 0.009 & -0.006 & -0.016 & 0.020 \\
\hline KUC12 & 130.20010 & 30.47958 & 29.5 & -0.001 & 0.003 & -0.041 & 0.014 \\
\hline KUC13 & 130.16418 & 30.48463 & 86.9 & - & - & - & - \\
\hline KUC14 & 130.21499 & 30.44178 & 620.1 & -0.023 & 0.012 & 0.001 & 0.033 \\
\hline KUC15 & 130.21464 & 30.44484 & 552.4 & -0.124 & -0.110 & 0.112 & 0.036 \\
\hline
\end{tabular}

The values of uncertainty of change in baseline length were set as the criteria of errors of horizontal displacements $\left(e x_{i}, e y_{i}\right)$, and errors of vertical displacements $\left(e h_{i}\right)$ were set to be three times of these values (i.e., $e h_{i}=3 e x_{i}=3 e y_{i}$ ) as described in the text 


$$
\rho=1.2861+0.5498 V_{\mathrm{P}}-0.0930 V_{\mathrm{P}}^{2}+0.007 V_{\mathrm{P}}^{3} .
$$

From Eqs. (1) and (2), modulus of rigidity can be calculated using the one-dimensional P-wave velocity structure as shown in Table 2. Based on the obtained values, we assumed a stratified structure as shown in Fig. 6, and applied to our FE domain.

\section{Deformation source analysis}

As we mentioned in "Characteristics of ground deformation" section, observed deformation was mostly radial patterns centered around Shin-dake crater, although there were some exceptions. Therefore, we applied a vertical spheroid source model. In order to minimize the difference between observation and calculation, we defined the $f$ function as follows:

$$
\begin{aligned}
f= & \sum_{i=1}^{n}\left[\left(\frac{d x_{i}^{\mathrm{obs}}-d x_{i}^{\mathrm{cal}}}{e x_{i}}\right)^{2}+\left(\frac{d y_{i}^{\mathrm{obs}}-d y_{i}^{\mathrm{cal}}}{e y_{i}}\right)^{2}\right. \\
& \left.+\left(\frac{d h_{i}^{\mathrm{obs}}-d h_{i}^{\mathrm{cal}}}{e h_{i}}\right)^{2}\right]
\end{aligned}
$$

where $d x_{i}, d y_{i}$, and $d h_{i}$ are east-west, north-south, and up-down components of relative displacements at benchmark $i$ with respect to KUCG; $e x_{i}, e y_{i}$, and $e h_{i}$ are east-west, north-south, and up-down components of observation error; $n(=13)$ is number of benchmarks

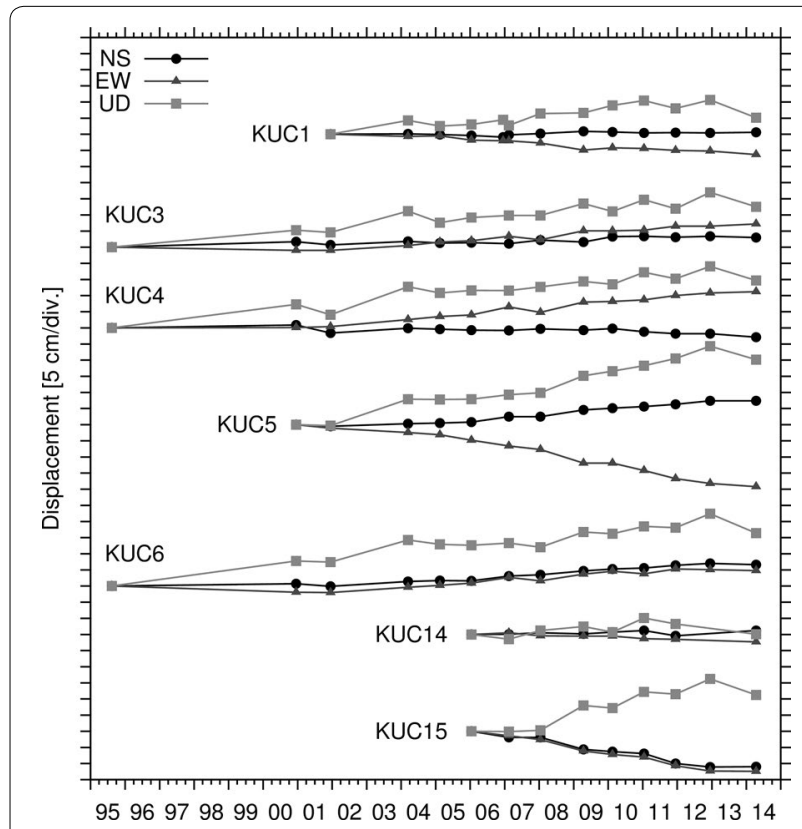

Fig. 3 Temporal change of in relative displacement of benchmarks with respect to KUCG during 1995-2014

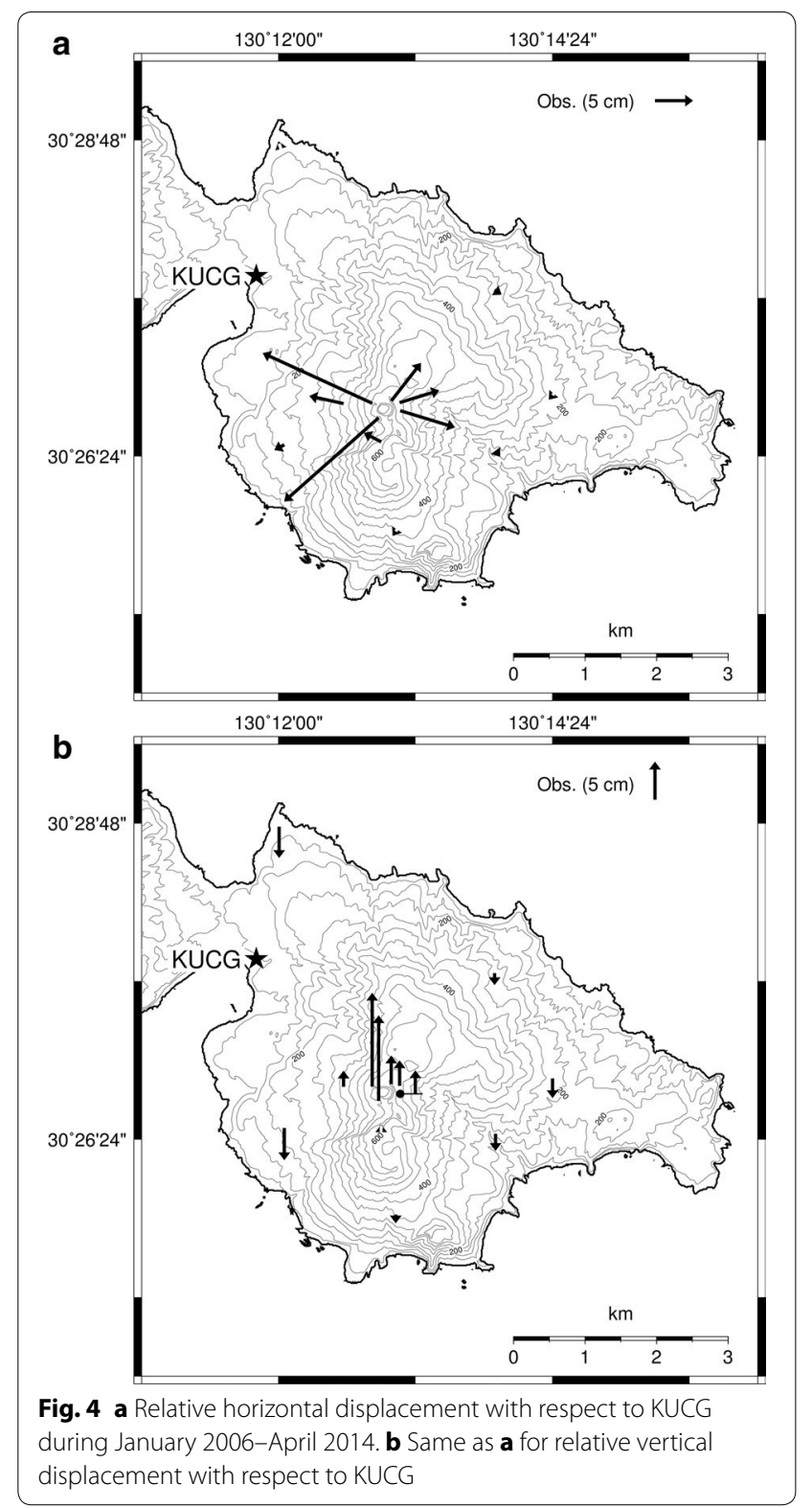

except the reference station KUCG; and superscript obs and cal indicates observations and calculations. Since Leica Geo Office provided only uncertainty of baseline length as the observation error this time, we used this value as the criteria of observation error. Errors of horizontal displacements $\left(e x_{i}, e y_{i}\right)$ are set to be uncertainty of change in baseline length (i.e., $e x_{i}=e y_{i}=$ uncertainty of change in baseline length). Errors of vertical components of GPS observation are generally approximately three times larger than those of horizontal components (e.g., Larson et al. 2007). Therefore, we set errors of vertical displacements $\left(e h_{i}\right)$ to be three times of uncertainty of change in baseline length (i.e., $e h_{i}=3 e x_{i}=3 e y_{i}$ ). We 


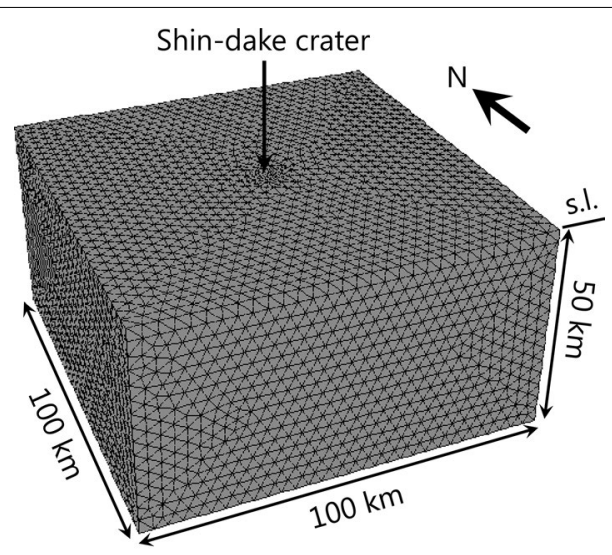

Fig. 5 FE domain set in the present study

set search range and step of each parameter as shown in Table 3. We searched the optimal values of horizontal location, depth, equatorial and polar radiuses, and internal pressure change of the source which minimize the $f$ value between observed and calculated relative displacements with respect to KUCG using the forward modeling method. We set the initial location and depth of the source at Shin-dake crater and at $300 \mathrm{~m}$ below the crater bottom (i.e., $200 \mathrm{~m}$ asl), respectively, in accordance with the previous result (Iguchi et al. 2007), and searched an optimal set of model parameters by changing parameter values gradually.

\section{Results}

The obtained optimal values and 95\% confidence intervals for each parameter and minimum $f$ value are shown in Table 3, and Fig. 7a indicates source location and comparison of observed and calculated relative horizontal displacements. A vertical spheroid source with both equatorial and polar radiuses of $50 \mathrm{~m}$ (i.e., a spherical source with a radius of $50 \mathrm{~m}$ ) was obtained beneath Shin-dake crater at a depth of $400 \mathrm{~m}$ above sea level (asl)

Table 2 One-dimensional P-wave velocity structure of Kuchinoerabu-jima (Yamamoto et al. 2005; Triastuty et al. 2009), and calculated modulus of rigidity from Eqs. (1) and (2)

\begin{tabular}{llc}
\hline Depth $(\mathbf{k m}$ bsl) & $\boldsymbol{V}_{\mathbf{P}}(\mathbf{k m} / \mathbf{s})$ & $\boldsymbol{\mu}(\mathrm{GPa})$ \\
\hline-1.0 & 2.22 & 3.49 \\
-0.5 & 2.49 & 4.52 \\
0.0 & 3.12 & 7.49 \\
0.5 & 4.00 & 13.0 \\
1.0 & 4.30 & 15.3 \\
2.0 & 5.00 & 21.5 \\
3.0 & 5.35 & 25.2 \\
\hline
\end{tabular}

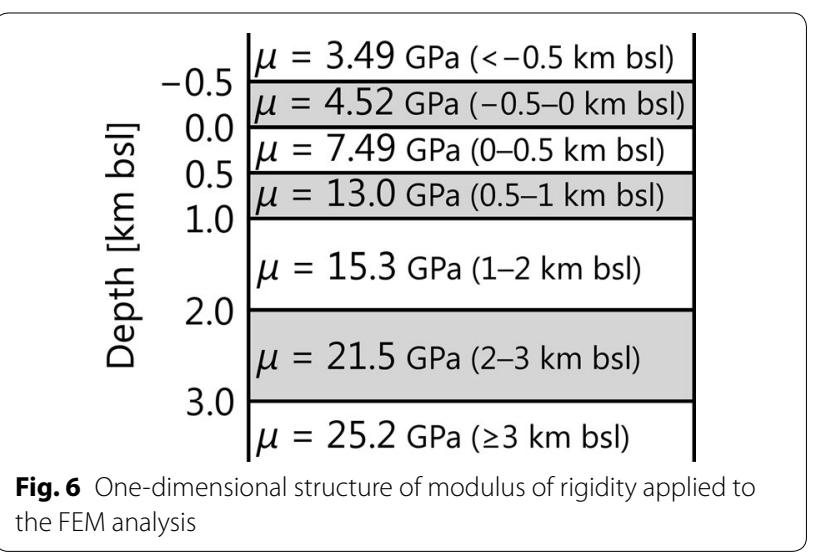

(i.e., at a depth of approximately $100 \mathrm{~m}$ below the crater bottom). Figure 8 shows grid maps of the $f$ value between parameter spaces. The parameters for the source are well constrained for the obtained values. The pressure increase of $361 \mathrm{MPa}$ yields volume increase of $31,700 \mathrm{~m}^{3}$. The obtained spherical source can explain overall horizontal deformations: radial deformation patterns around Shin-dake crater, larger displacements at western rim compared to eastern one, and westward deformation at KUC14, as well as small deformation at the foot of Shindake and Furu-dake (Fig. 7a). Although there are some differences between observed and calculated vertical deformations due to their large errors, vertical deformation can be explained within the differences of approximately $\pm 5 \mathrm{~cm}$ (Fig. 7b).

\section{Discussion}

Applying an FEM, a shallow spherical source with a radius of $50 \mathrm{~m}$ was obtained beneath Shin-dake crater at a depth of $400 \mathrm{~m}$ asl, i.e., at a depth of approximately $100 \mathrm{~m}$ below the crater bottom. According to Lisowski (2007), strain $\Delta P / \mu$ (where $\Delta P$ is internal pressure change; and $\mu$ is modulus of rigidity) ranges from $10^{-3}$ to $10^{-1}$, and the higher value is beyond the typical elastic limit of crustal rocks. The obtained source is within the layer with a modulus of rigidity of $4.52 \mathrm{GPa}$. The internal pressure change of $+361 \mathrm{MPa}$ yields corresponding strain $\Delta P / \mu$ of 0.0799 . This value is within the range from $10^{-3}$ to $10^{-1}$, but possibly beyond the typical elastic limit of crustal rocks. Before the eruption on August 3, 2014, surrounding rocks of the source might have shown plastic behavior rather than elastic one. The eruption might have caused when the strain reached their fracture point.

We tested a Mogi model (Mogi 1958), as the previous studies did, to the deformation during January 2006April 2014 for the purpose of comparing with the result of an FEM. We corrected the topographical effect by 
Table 3 Search range and step, optimal value, and the minimum $f$ value for each parameter

\begin{tabular}{|c|c|c|c|c|c|}
\hline \multirow[t]{2}{*}{ Parameter } & \multirow[t]{2}{*}{ Search range } & \multirow[t]{2}{*}{ Step } & \multicolumn{3}{|c|}{ Optimal value for each model } \\
\hline & & & FEM & Mogi & Dislocation \\
\hline E-W location & -500 to $500 \mathrm{~m}$ & $50 \mathrm{~m}$ & $0 \pm 50 \mathrm{~m}$ & $-50 \pm 50 m$ & $-50 \pm 50 m$ \\
\hline $\mathrm{N}-\mathrm{S}$ location & -500 to $500 \mathrm{~m}$ & $50 \mathrm{~m}$ & $0 \pm 50 \mathrm{~m}$ & $0 \pm 50 \mathrm{~m}$ & $0 \pm 0 \mathrm{~m}$ \\
\hline Depth & $500 \mathrm{~m}$ asl-500 m bsl & $50 \mathrm{~m}$ & $400 \pm 0 \mathrm{~m}$ asl & $450 \pm 50 \mathrm{~m}$ asl & $500 \pm 0 \mathrm{~m}$ asl \\
\hline Equatorial radius & $50-200 \mathrm{~m}$ & $50 \mathrm{~m}$ & $50 \pm 0 \mathrm{~m}$ & - & - \\
\hline Polar radius & $50-200 \mathrm{~m}$ & $50 \mathrm{~m}$ & $50 \pm 0 \mathrm{~m}$ & - & - \\
\hline Internal pressure change & +1 to $+500 \mathrm{MPa}$ & $1 \mathrm{MPa}$ & $+361 \pm 133 \mathrm{MPa}$ & - & - \\
\hline Dip & $0^{\circ}-90^{\circ}$ & $1^{\circ}$ & - & - & $74 \pm 15^{\circ}$ \\
\hline Strike & $0^{\circ}-359^{\circ}$ & $1^{\circ}$ & - & - & $165 \pm 12^{\circ}$ \\
\hline Length & $50-500 \mathrm{~m}$ & $50 \mathrm{~m}$ & - & - & $150 \pm 50 m$ \\
\hline Width & $50-500 \mathrm{~m}$ & $50 \mathrm{~m}$ & - & - & $150+250 /-50 m$ \\
\hline Opening & $0.01-5.00 \mathrm{~m}$ & $0.01 \mathrm{~m}$ & - & - & $1.86 \pm 0.72 \mathrm{~m}$ \\
\hline Volume change & +100 to $+50,000 \mathrm{~m}^{3}$ & $100 \mathrm{~m}^{3}$ & $\left(+31,700 \mathrm{~m}^{3}\right)$ & $+25,400 \pm 8800 \mathrm{~m}^{3}$ & $\left(+41,850 \mathrm{~m}^{3}\right)$ \\
\hline The minimum $f$ value & - & - & 87.2 & 99.5 & 78.0 \\
\hline
\end{tabular}

The origin of the horizontal coordinate is set at Shin-dake crater $\left(130.21539^{\circ} \mathrm{E}, 30.44593^{\circ} \mathrm{N}\right)$. The position of the dislocation model is at the center of the top edge of the fault. The dip is clockwise from the horizontal and the strike is clockwise from the north. The uncertainties are the $95 \%$ confidence intervals estimated from the $F$ test (Árnadóttir and Segall 1994)

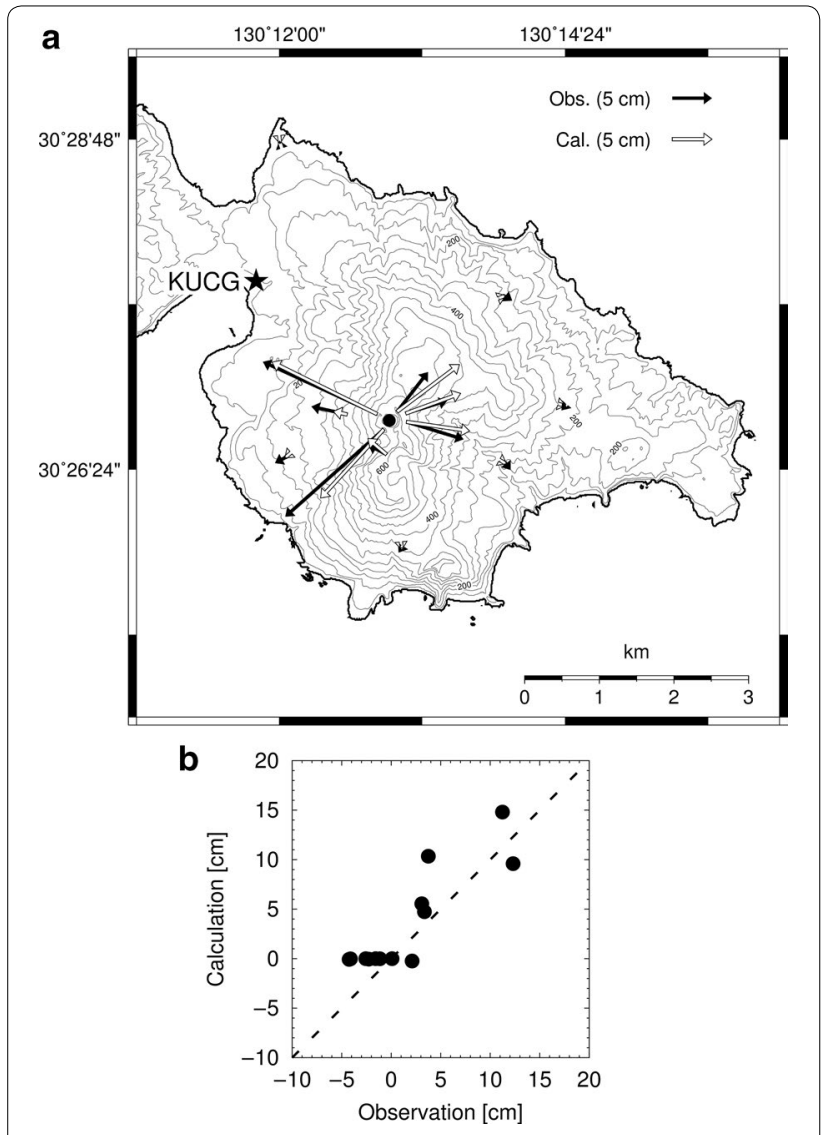

Fig. 7 a Location of obtained deformation source (solid circle) and comparison of observed and calculated relative horizontal displacements with respect to KUCG (black and white arrows, respectively). b Comparison of observed and calculated relative vertical displacements with respect to KUCG adding the elevations of the benchmarks to the source depth (Williams and Wadge 1998). We searched an optimal set of model parameters by a grid search method. The obtained optimal values and 95\% confidence intervals for each parameter and the minimum $f$ value are shown in Table 3, and source location and comparison of observed and calculated relative displacements with respect to KUCG are shown in Fig. 9. An inflation source was obtained beneath Shin-dake crater at a depth of $450 \mathrm{~m}$ asl, similarly to that of the result using an FEM. Although the Mogi model can explain crater-centered radial horizontal displacements around Shin-dake crater or small displacement at the foot, there are some differences between observation and calculation. Especially, westward displacement at KUC14 cannot be explained by Mogi model. The minimum $f$ value for FEM model is approximately $12 \%$ smaller compared to that of Mogi model. Furthermore, its volume increase of $25,400 \mathrm{~m}^{3}$ yields its radial increase of $18 \mathrm{~m}$ if the original radius is zero (point source), which is too large under the assumption of Mogi model at extremely shallow depth.

Figure 9a seems to indicate that a NNW-SSE striking dike with a dip toward the west may also explain the deformation. Therefore, we applied the dislocation model for a half-infinite homogeneous elastic solid assuming a Poisson's ratio of 0.25 (Okada 1992). We searched an optimal set of model parameters similarly to Mogi model. The obtained optimal values and $95 \%$ confidence intervals for each parameter and the minimum $f$ value are shown in Table 3, and source location and comparison of observed and calculated relative displacements with 


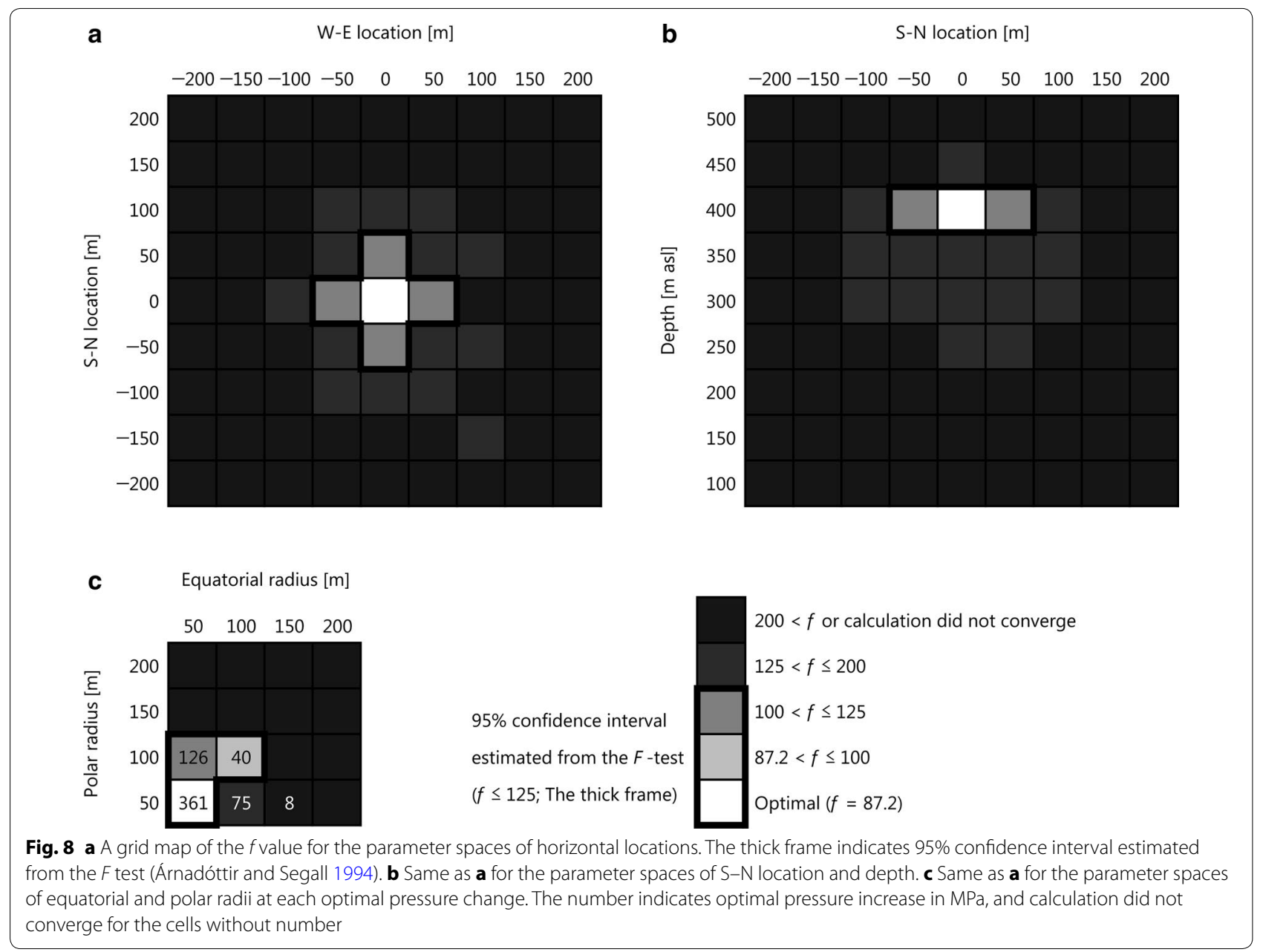

respect to KUCG are shown in Fig. 10. The obtained dike can explain crater-centered radial horizontal displacements around Shin-dake crater or small displacement at the foot, and it provided the lowest $f$ value among three models we applied. However, this model still cannot explain westward displacement at KUC14. In addition, this model cannot explain the tilt change at SDN tilt station before the eruption on August 3, 2014 as we will discuss later.

The location of obtained spherical deformation source using an FEM is similar to that obtained by previous studies (e.g., Iguchi et al. 2007) or our result based on Mogi model. Our result using an FEM, however, obtained the shape of the source as a sphere with a radius of $50 \mathrm{~m}$ (i.e., a diameter of $100 \mathrm{~m}$ ), and the source can explain overall deformation, differently to the previous results or our result based on Mogi model. Especially, the location of KUC14, which showed a westward displacement, is a steep topography near the cliff, and should be highly affected by the topography preventing its reproduction by Mogi model.

Hypocenters of shallow volcano-tectonic (VT) earthquakes in 2006 estimated by Triastuty et al. (2009) are distributed at depths of 200-600 m asl beneath Shindake crater and coincide with the size and location of the obtained deformation source. They suggested that shallow VT earthquakes were caused by the intrusion of hydrothermal fluids into cracks beneath the crater and extensional stress resulted by the shallow ground inflation source. Accumulation of strain in the rocks around 


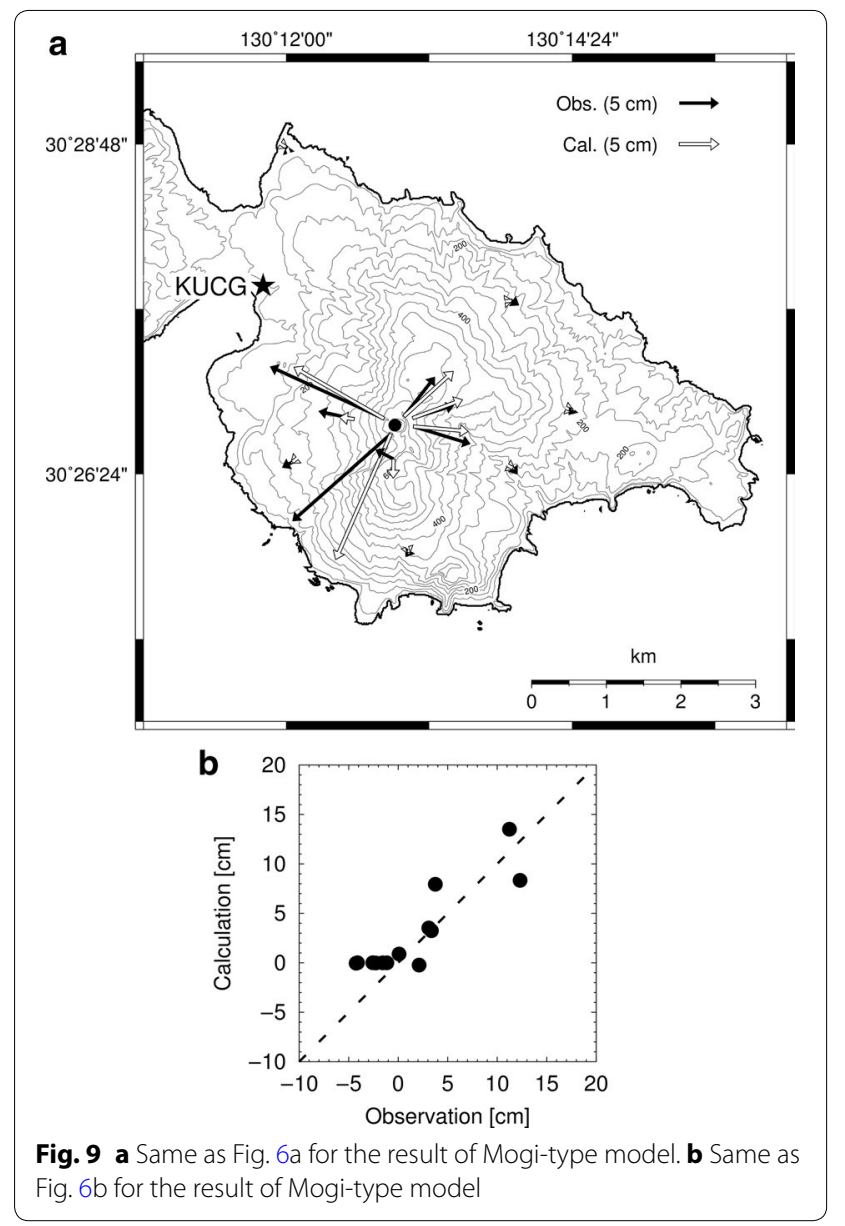

the pressurized deformation source may be one of the causes of the shallow VT earthquakes.

Kanda et al. (2010) obtained a two-dimensional resistivity model by audio-frequency magnetotellurics (AMT) method. They found two conductive regions: one is a shallow and thin conductive layer near the surface beneath the summit area; the other is a deep and thick layer at depths of 200-800 m bsl. They inferred that these regions were conductive clay minerals which are formed by the elevated temperature beneath the area around the current active craters or corresponding to past edifices of Furu-dake and No-ike. Since such clay-rich layers are considered to be impermeable, meteoric water may have been accumulated around the upper boundary of deeper conductive layer and may have formed an aquifer. The obtained deformation source is located between the two clay-rich layers. High-temperature volcanic gas
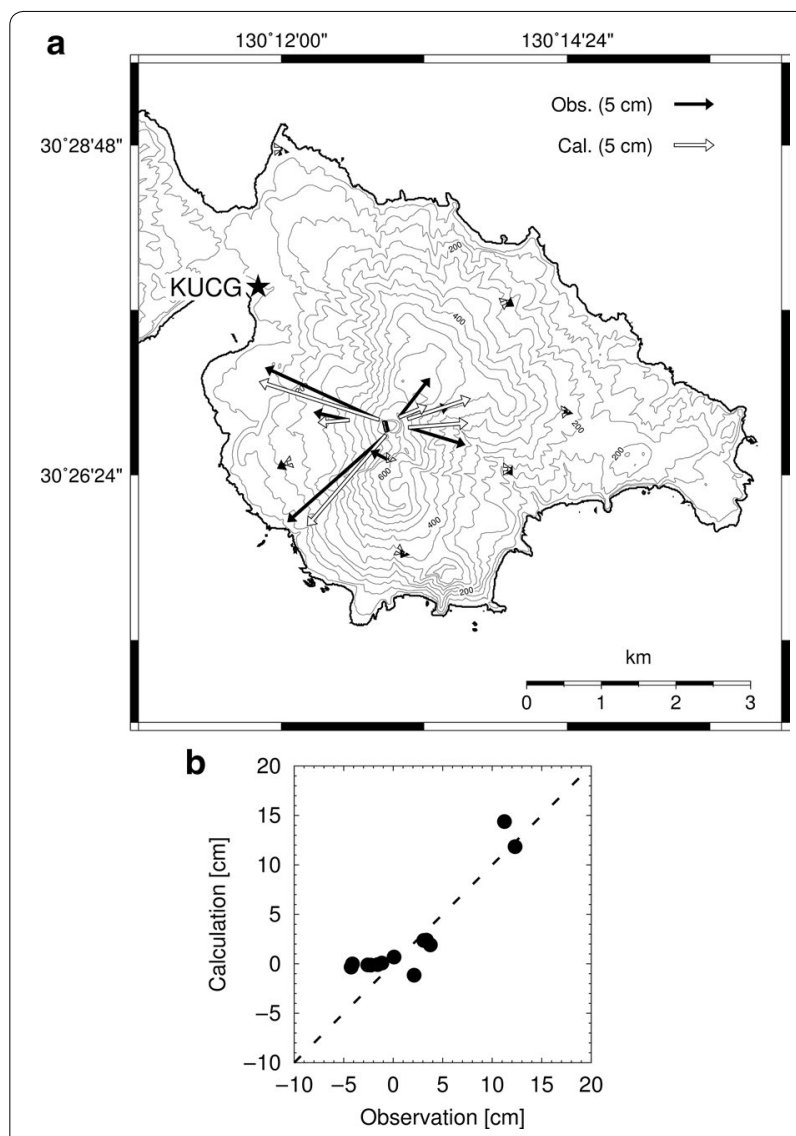

Fig. 10 a Same as Fig. 6a for the result of dislocation model. The solid rectangle indicates the obtained dike. The thick black line represents the top of the obtained dike. $\mathbf{b}$ Same as Fig. $6 \mathrm{~b}$ for the result of dike model

or hydrothermal fluid has been continually supplied from deeper part toward the aquifer, and pressurized rock around the aquifer may have produced demagnetization as Kanda et al. (2010) noted. The obtained deformation source may be corresponding to the pressurized part of the aquifer.

We also applied the obtained spherical deformation source to the precursor tilt change at SDN tilt station located at north rim of Shin-dake crater, before the eruption on August 3, 2014 (Fig. 11a). The tilt change started at around 11:00 AM (local time; the same hereinafter), approximately one and half hour before the eruption. At around 12:00 PM, tilt change accelerated, and the eruption occurred at 12:24 PM. In total, uplift of southwest direction with tilt change of approximately $12.2 \mu \mathrm{rad}$ was 


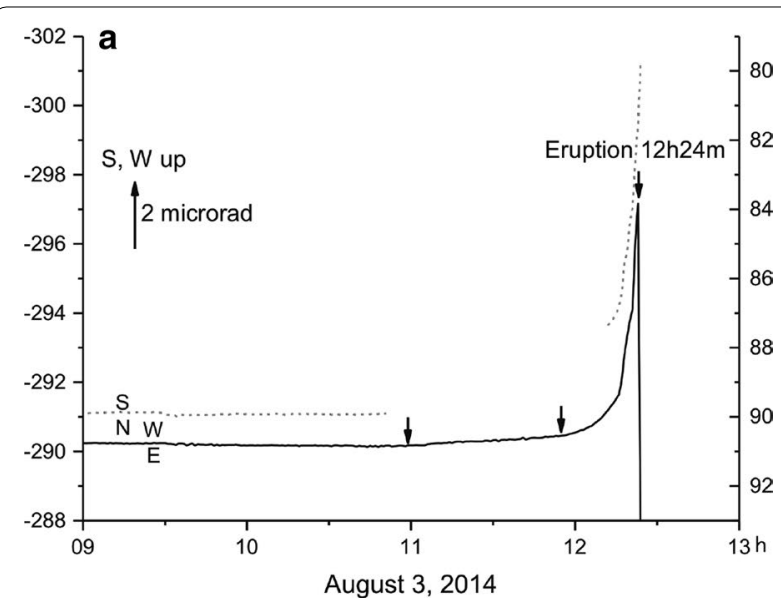

b

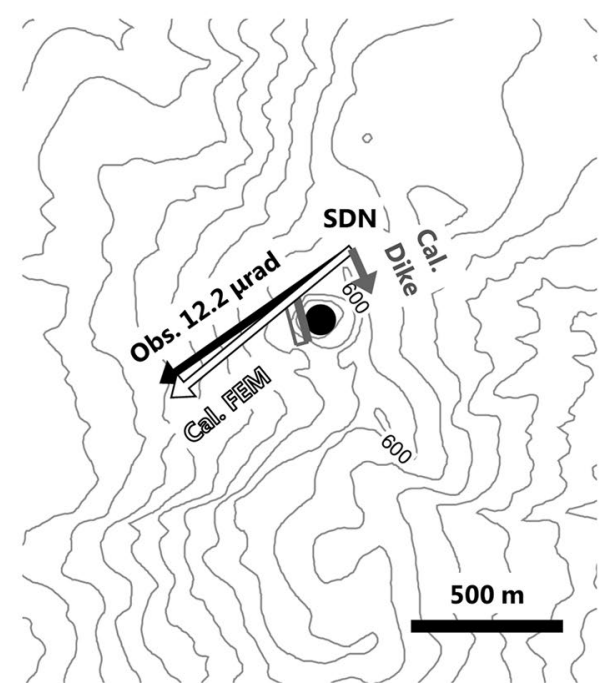

Fig. 11 a Tilt change at SDN on August 3, 2014 (Iguchi et al. 2017). b Observed tilt during 11:00 AM-12:24 PM (the black arrow) and calculated tilt (white and gray arrows) at SDN applying the obtained FEM spherical source (solid circle) and dike (gray rectangle), respectively

observed. This tilt change can be explained by pressure increase of $6 \mathrm{MPa}$ in the obtained spherical deformation source (Fig. 11b). This internal pressure increase yields volume increase of $520 \mathrm{~m}^{3}$. In $1.5 \mathrm{~h}$ before the eruption, $520 \mathrm{~m}^{3}$ of volcanic materials were considered to be supplied toward shallower. We also tried to apply the obtained dike, but this model cannot explain the tilt change at its optimal opening $(5 \mathrm{~cm})$ as shown in Fig. 11b.

Yamamoto et al. (2017) obtained the depth of inflation source during the period between August 2014 and March 2015 to be $7.0 \mathrm{~km}$ bsl beneath Shin-dake crater from the data of precise leveling surveys. They obtained volume increase as $+2.6 \times 10^{6} \mathrm{~m}^{3}$, two orders of magnitude greater than our result during the period between January 2006 and April 2014. A cross-sectional profile of the Kuchinoerabu-jima with deformation sources during the periods between January 2006 and April 2014, and between August 2014 and March 2015, with VT earthquakes zone is described in Fig. 12. Before the eruption on August 3, 2014, volcanic gas or hydrothermal fluid accumulated from deeper toward shallower at a depth of $400 \mathrm{~m}$ asl which caused VT earthquakes beneath Shin-dake crater. On the other hand, magma may have accumulated at a deeper part before the eruption on May 29, 2015, and its amount was two orders of magnitude greater than that accumulated toward shallower part before the eruption on August 3, 2014. Besides, magma migration from this deeper reservoir toward shallower may have occurred during the period between December 2014 and January 2015 as Iguchi et al. (2017) indicated from baseline shortening between eastern roof of Shin-dake and Yakushima which cannot be explained by the inflation of deeper source (Yamamoto et al. 2017) as well as increase in $\mathrm{SO}_{2}$ emission during this period.

\section{Conclusions}

An FEM allowed reproduction of overall deformation in Kuchinoerabu-jima, and to obtain more precise shape and depth of the deformation source, a spherical source with a radius of $50 \mathrm{~m}$. Ground deformation is highly affected by the surface topography when the surface topography is steep, such as KUC14 which locates near the cliff.

The obtained deformation source may be corresponding to the pressurized aquifer, and shallow VT earthquakes and demagnetization may be caused by pressure and strain accumulation in the rocks around the aquifer.

Applying the obtained spherical source to the tilt change before August 3, 2014 eruption, we found that $520 \mathrm{~m}^{3}$ of volcanic materials were supplied toward shallower in $1.5 \mathrm{~h}$ before the eruption. The depth and volume 


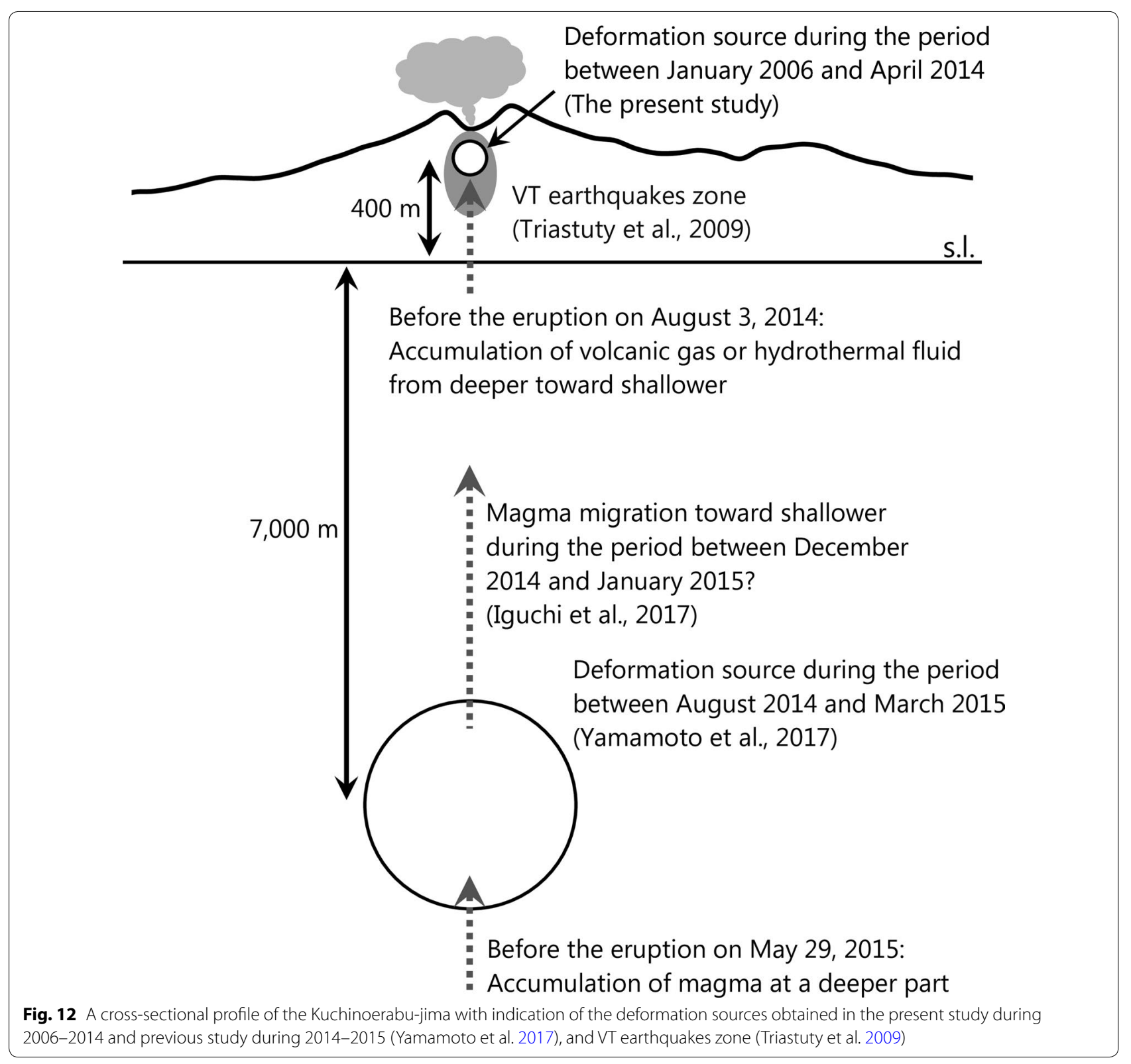

change of deformation source before May 2015 eruption is deeper and two orders of magnitude greater compared to that before August 2014 eruption.

\section{Abbreviations}

GPS: Global Positioning System; bsl: below sea level; FEM: finite element method; DEM: digital elevation model; asl: above sea level; VT: volcano-tectonic; AMT: audio-frequency magnetotellurics.

\section{Authors' contributions}

$\mathrm{KH}$ participated in the study conception and design, acquisition, analysis and interpretation of data, and drafted the manuscript. Ml participated in the study conception and design, acquisition and analysis of data, and helped to draft the manuscript with critical revisions. Both authors read and approved the final manuscript.

\section{Acknowledgements}

Some of the figures in this paper were prepared using generic mapping tools (Wessel and Smith 1995) and JPGIS data from the Geospatial Information Authority of Japan. We used DEM data provided by Kagoshima prefecture and elevation information from Google map in the present study. We also thank

Dr. Yosuke Aoki and two anonymous reviewers for their helpful comments.

\section{Competing interests}

The authors declare that they have no competing interests.

\section{Availability of data and materials}

The datasets supporting the conclusions of this article are included within the article.

\section{Consent for publication}

Not applicable. 
Ethics approval and consent to participate

Not applicable.

\section{Funding}

This study was supported by the Ministry of Education, Culture, Sports, Science and Technology (MEXT) of Japan under its 7th Plan of Volcanic Eruption Prediction (2004-2008) and Earthquake and Volcano Hazards Observation and Research Program (2009-2013) and was supported by a grant for collaborative research from Disaster Prevention Research Institute (DPRI), Kyoto University.

\section{Publisher's Note}

Springer Nature remains neutral with regard to jurisdictional claims in published maps and institutional affiliations.

Received: 27 July 2017 Accepted: 14 December 2017

Published online: 22 December 2017

\section{References}

Árnadóttir T, Segall P (1994) The 1989 Loma Prieta earthquake imaged from inversion of geodetic data. J Geophys Res Solid Earth 99(B11):21835-21855

Currenti G, Del Negro C, Ganci G (2007) Modeling o ground deformation and gravity fields using finite element method: an application to Etna volcano. Geophys J Int 169:775-786. https://doi. org/10.1111/j.1365-246X.2007.03380.x

Iguchi M (2007) Detection of change of anomalorea by aerial infrared thermal measurements at Kuchinoerabujima volcano. Report of project on practical study on prediction of phreatic eruption and its change at Kuchinoerabujima Volcano, Japan. Disaster Prevention Research Institute, Kyoto University, Kyoto, pp 45-50 (in Japanese)

Iguchi M, Nakamichi H (2015) Successive occurrence of phreatic eruptions in Japan. Ann Disaster Prev Res Inst Kyoto Univ 58(A):1-7 (in Japanese with English abstract)

Iguchi M, Saito E, Tameguri T, Triastuty E, Yamazaki T (2007) Evaluation of volcanic activity of Kuchinoerabujima in 2006. Ann Disaster Prev Res Inst Kyoto Univ 50(B):349-357 (in Japanese with English abstract)

Iguchi M, Nakamichi H, Tameguri T, Yamamoto K, Mori T, Ohminato T, Saito E (2017) Contribution of monitoring data to decision making for evacuation from the 2014 and 2015 eruptions of Kuchinoerabujima Volcano. J Nat Disaster Sci 38(1):31-47
Kanda W, Utsugi M, Tanaka Y, Hashimoto T, Fujii I, Hasenaka T, Sigeno N (2010) A heating process of Kuchi-erabu-jima volcano, Japan, as inferred from geomagnetic field variations and electrical structure. J Volcanol Geotherm Res 189:158-171. https://doi.org/10.1026/j.jvolgeores.2009.11.002

Larson KM, Kostoglodov V, Miyazaki S, Santiago JAS (2007) The 2006 aseismic slow slip event in Guerrero, Mexico: new results from GPS. Geophys Res Lett 34:L13309. https://doi.org/10.1029/2007GL029912

Lisowski M (2007) Analytical volcano deformation source models. In: Volcano deformation, Chap 8. Springer, Berlin, pp 279-304. https://doi. org/10.1007/978-3-540-49302-0

Mogi K (1958) Relations between the eruptions of various volcanoes and the deformations of the ground surfaces around them. Bull Earthq Res Inst 36:99-134

Okada Y (1992) Internal deformation due to shear and tensile faults in a half space. Bull Seismol Soc Am 82(2):1018-1040

Ronchin E, Geyer A, Martí J (2015) Evaluating topographic effects on ground deformation: insights from finite element modeling. Surv Geophys 36:513-548. https://doi.org/10.1007/s10712-015-9325-3

Triastuty H, Iguchi M, Tameguri T (2009) Temporal change of characteristics of shallow volcano tectonic earthquakes associated with increase in volcanic activity at Kuchinoerabu Volcano, Japan. J Volcanol Geotherm Res 187:1-12. https://doi.org/10.1026/j.jvolgeores.2009.05.017

Wessel P, Smith WHF (1995) New version of Generic Mapping Tools released. EOS Trans AGU 76:329

Williams CA, Wadge G (1998) The effects of topography on magma chamber deformation models: application to Mt. Etna and radar interferometry. Geophys Res Lett 25(10):1549-1552. https://doi.org/10.1029/98gl01136

Yamamoto K, Iguchi M, Hashimoto M, Tsutsui T, Tanaka S, Aoki Y, Onizawa S, Watanabe T, Shimizu H, Ohkura T, Miyamachi H, Yakiwara H, Hiramatsu $H(2005)$ Analysis of seismic velocity structures using the data of 2004 Kuchinoerabujima volcano active seismic survey. In: Japan earth and planetary science joint meeting 2005, V055-P028 (abstract)

Yamamoto K, Ohkura T, Yokoo A, Tameguri T, Sonoda T, Inoue H (2017) Vertical ground deformation related to the 2014 and 2015 eruptions at Kuchinoerabujima Volcano, Japan detected by repeated precise leveling surveys. J Nat Disaster Sci 38(1):133-144

Zhao S, Müller RD, Takahashi Y, Kaneda Y (2004) 3-D finite-element modelling of deformation and stress associated with faulting: effect of inhomogeneous crustal structures. Geophys J Int 157:629-644. https://doi. org/10.1111/j.1365-246X.2004.02200.x

\section{Submit your manuscript to a SpringerOpen ${ }^{\circ}$ journal and benefit from:}

- Convenient online submission

- Rigorous peer review

- Open access: articles freely available online

- High visibility within the field

Retaining the copyright to your article

Submit your next manuscript at springeropen.com 